\title{
Abundance and habitat-suitability relationship deteriorate in fragmented forest landscapes: a case of Adinandra griffithii Dyer, a threatened endemic tree from Meghalaya in northeast India
}

\author{
Dibyendu Adhikari ${ }^{1}$, Aabid Hussain Mir ${ }^{2}$, Krishna Upadhaya ${ }^{3 *}$, Viheno Iralu ${ }^{2}$ and Dilip Kumar Roy ${ }^{4}$
}

\begin{abstract}
Introduction: A strong positive 'abundance and habitat-suitability' relationship is crucial for conservation of species. Nevertheless, anthropogenic alteration of natural landscapes leading to land use and land cover change, habitat loss, and species extinctions (may) have putatively disturbed this relationship. Hence, it is important to study the nature of the relationship in such human influenced landscapes.

Methods: In this study, we endeavored to understand the consistency of the relationship in the fragmented natural landscapes in the Khasi, Garo, and Jaintia hills of Meghalaya in northeast India, with Adinandra griffithii (an endangered endemic tree) as a model species. We reconstructed the distribution of its suitable habitats as a function of the remotely sensed vegetation phenology (i.e., EVI data), using point occurrence data and ecological niche modeling (ENM) tool. Estimation of the abundance and habitat characterization was done through field surveys following standard methods.

Results: The study revealed that remotely sensed landscape-level vegetation phenology could effectively discriminate the suitable and unsuitable habitats of threatened species. Linear regression model showed a weak positive correlation between abundance and predicted habitat suitability for adult trees indicating (plausible) deterioration in the relationship. However, sapling and seedling populations did not show a precise trend in this respect. Field-based studies revealed that removal of the species from the suitable habitats because of anthropogenic disturbances possibly weakened the abundance-suitability relationship.
\end{abstract}

Conclusions: The findings of the study enjoin the need for re-establishment of the species in the suitable areas for its conservation and perpetuation.

Keywords: Abundant-center hypothesis, Species abundance, Habitat suitability, EVI, ENM

\section{Introduction}

Studying abundance and distribution pattern is crucial for species conservation planning (Sagarin et al. 2006). In this context, the abundant-center hypothesis posits that species abundance peaks in the center of its distributional range and decline in the edges (Wulff 1950; Whittaker 1975; Hengeveld and Haeck 1982). The high

\footnotetext{
*Correspondence: upkri@yahoo.com

${ }^{3}$ Department of Basic Sciences and Social Sciences, North-Eastern Hill

University, Shillong 793022, India

Full list of author information is available at the end of the article
}

abundance in the center is because of the optimal conditions viz., the presence of suitable habitats, while the decline in abundance in its range edges is because of environmental sub-optimality (Lira-Noriega and Manthey 2014). Therefore, in a geographical sense, the hypothesis pronounces that species abundance (A) is directly proportional to habitat suitability (S) (Weber et al. 2016). Overall, this pattern is consistent in natural landscapes (Brown 1984).

A resilient AS relationship is crucial for species conservation as it helps in addressing the issues related to 
landscape-level conservation, reintroductions, population connectivity, habitat restoration and management, and protected area delineation (Fischer and Lindenmayer 2007). Nonetheless, anthropogenic activities such as over-exploitation, habitat destruction, and fragmentation of forest areas have substantially altered the natural landscapes affecting the distribution of species populations and habitats (Hansen et al. 2013). These influences have brought at least one-fifth of the plant species to the brink of extinction (Brummitt and Bachman 2010), putatively affecting the AS relationship (Fischer and Lindenmayer 2007). The nature of the relationship in humanaltered landscapes is not clearly understood, and therefore deserves a detailed and systematic study.

Assessing the strength of AS relationship for a species in a given landscape requires (i) knowledge on the distributional range and potential habitats, and (ii) quantifying the abundance in the entire distributional range (Sagarin and Gaines 2002). Availability of satellite data of better spatial and temporal resolution, and geographical information system (GIS), ecological niche modeling
(ENM), and habitat modeling tools have helped in the delineation of potential habitats and geographical range to a high level of confidence, making it convenient to study the AS pattern (Weber et al. 2016). ENM reconstructs the niche of species in an ecological space by correlating the occurrence data with a set of rasterized environmental variables. The modeled niche can be translated into a potential distribution area map (Peterson 2011). Such models help in understanding the ecological and geographic extents of species distribution (Peterson 2001), and has been used to guide biodiversity surveys and for delineating areas for conservation of threatened species (Adhikari et al. 2012).

The present study was carried out in the Khasi, Garo, and Jaintia hills of Meghalaya in northeast India. The region is a part of the Indo-Burma biodiversity hotspot and is a transition zone between the Indian, IndoMalayan, and Indo-Chinese biogeographic zones. Historically, large tracts of the study area were covered by subtropical broadleaf forests (Champion and Seth 1968). However, during last three decades, these areas became
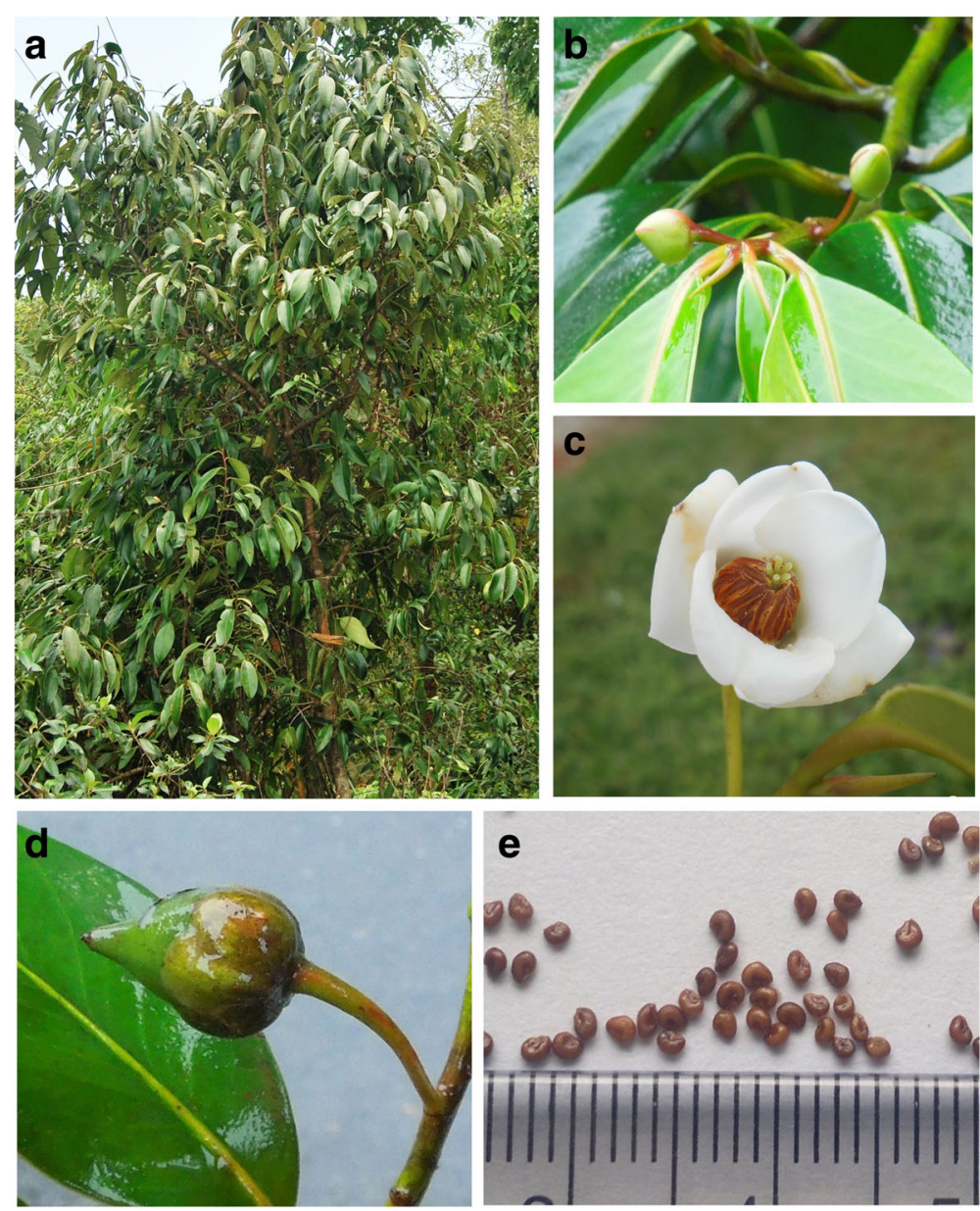

Fig. 1 Adinandra griffithii. a A mature tree. b Flower initiation. c Flower. d Fruit and e Seeds 
highly fragmented due to various anthropogenic activities (Roy and Tomar 2001), resulting in habitat loss of at least 274 endemic plants (Upadhaya et al. 2013). As a model species, we selected Adinandra griffithii-an endangered endemic tree of the region (World Conservation Monitoring Centre 1998; Nayar and Sastry 1987; Haridasan and Rao 1985). The species is admired for its fragrant flowers and is a good timber species (Nayar and Sastry 1987). Information on its ecology, potential distribution areas, habitat preferences, and population status is limited as the species was last collected in the year 1938 (Nayar and Sastry 1987). The specific objectives were (i) to model the distribution of potential habitats, (ii) to assess the population and abundance pattern in the predicted areas, (iii) to characterize the habitats, and (iv) to study the relationship between abundance and habitat suitability.

\section{Methods}

Study species

Adinandra griffithii Dyer (Family Pentaphylacaceae) is a globally endangered $(\mathrm{A} 1 \mathrm{c}, \mathrm{B} 1+2 \mathrm{c})$ tree species. It attains a height of $\sim 15 \mathrm{~m}$ and has coriaceous leaves, solitary fragrant flowers, and ovoid berry-like fruits. The fruit measures $\sim 1.5 \mathrm{~cm}$ across containing numerous seeds. Seeds are kidney-shaped measuring $\sim 0.1$ to $1.5 \mathrm{~mm}$ across (Fig. 1). The flowering occurs during April to June, and fruiting during September to December (Balakrishnan 1981; Upadhaya et al. 2017).

\section{Population survey}

Population survey was undertaken following a gridbased approach. Two hundred and fifty-five grids of $0.1^{\circ} \times 0.1^{\circ}$ sizes (i.e., $\sim 1 \times 1 \mathrm{~km}$ ) were laid over the state of Meghalaya (Fig. 2). Thereafter, we selected 20 grids for the systematic survey based on expert opinion and historical record of species presence, i.e., herbarium records and published literature (World Conservation Monitoring Centre 1998; Nayar and Sastry 1987; Haridasan and Rao 1985). Extensive field surveys were undertaken in the selected grids during the year 2015 to locate natural populations of the species. The encountered individuals of $A$. griffithii were categorized as (i) adults $(\geq 5 \mathrm{~cm}$ diameter at breast height measured at

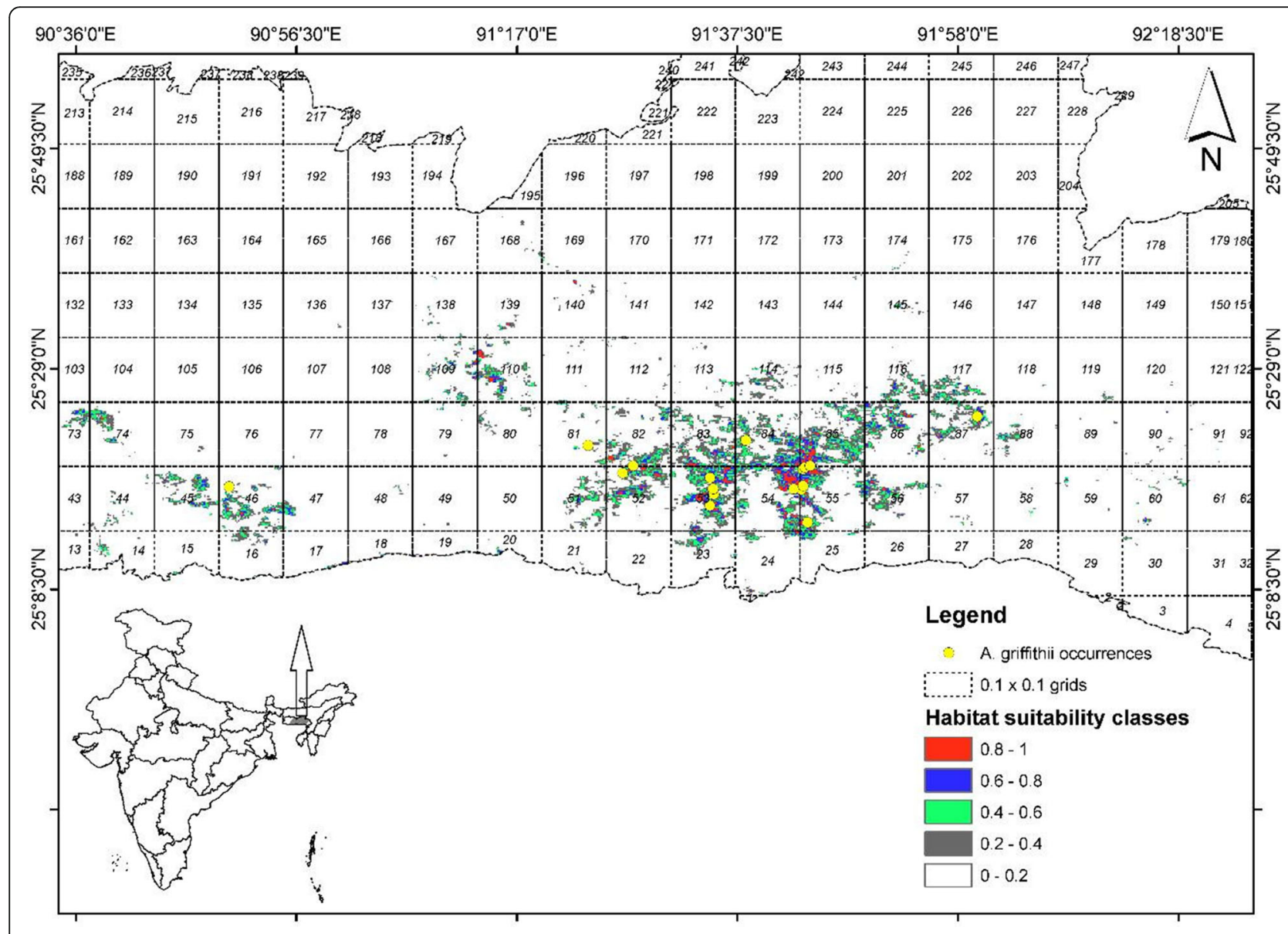

Fig. 2 Distribution of potential habitats of A. griffithii in the Garo, Khasi and Jaintia hills of Meghalaya. The italicized numerals in the map represent the grid numbers 
$1.37 \mathrm{~m}$ from the ground level), and (ii) saplings $(<5 \mathrm{~cm}$ $\mathrm{dbh}$ and $>1 \mathrm{~m}$ height), and (iii) seedlings ( $<1 \mathrm{~m}$ height). The abundance in each occurrence locality was expressed as a total count of the adults, saplings, and seedlings.

\section{Habitat distribution modeling Species occurrence data}

Geographical coordinates of 17 occurrence localities of A. griffithii were recorded from one National park (Balpakram National park), 5 sacred groves (Lum Shynna, Law Arliang Laitryngew, Law Khlieng, Law Sunnia, Law Lyngdoh Lynshing), 5 village forests (Umlangmar Law Shnong, Twah Sangparat, Khlaw Jingkieng, Law Adong Kynshuilid, Law Adong Thmai), and 6 protected forests owned by the local communities (Tyllong Um-Kyrwiang, Mawsynram village forest, Law Pjah, Law Adong Diengkynthong, Law Adong Phlangmawsyrpat, Law Adong Phud Juad) to an accuracy range from $\sim 5$ to $10 \mathrm{~m}$ using Garmin e-trex global positioning system (GPS) device.

\section{Predictor variables}

We used moderate resolution imaging spectroradiometer (MODIS) based enhanced vegetation index (EVI) data as a predictor of the potential habitats of $A$. griffithii. Compared to normalized difference vegetation index (NDVI), EVI serves as a better predictor of species potential areas in forested and undulating terrains because of its capability to discriminate spatial and temporal variations in vegetation (Setiawan et al. 2014). Twenty-one GeoTIFF EVI images for the study area at a spatial resolution of $250 \mathrm{~m}$ were downloaded from Oak Ridge National Laboratory Distributed Active Archive Centre using the online MODIS data-subsetting tool (http://daac.ornl.gov/, ORNL DAAC 2008). These images correspond to the year 2015 when the field surveys were undertaken, and summarize the spatial and temporal variations in the greenness of the study area at fortnightly intervals. We avoided using climatic predictors as their influence on species distribution is best defined at coarser resolutions, i.e., $>1 \mathrm{~km}$ (Waring et al. 2006). Topographic variables such as slope, aspect, and elevation were not used as EVI is sensitive to the influence of such variables, and their effects are indirectly represented in it (Matsushita et al. 2007). We performed correlation analysis for the 21 layers to check multicollinearity using ENMTools (Warren et al. 2010). Subsequently, the variables with correlation coefficient $\geq 0.8$ were discarded, and 13 uncorrelated variables were used as predictors. The selected data were re-sampled to a spatial resolution of $250 \mathrm{~m}$. The spatial resolution of the EVI data was chosen based on the assumption that a pixel resolution of $250 \times 250 \mathrm{~m}$ would equitably explain the latent environmental variations of the species potential habitat (Adhikari et al. 2012).

\section{Model calibration and evaluation}

Selection of appropriate calibration area extent is crucial in species distribution modeling, as it influences the model predictive capacity (Phillips et al. 2009; Giovanelli et al. 2010). It has been demonstrated that the area extents that have been historically accessible to the species are ideal for model development (Barve et al. 2011). Based on the historical account of the occurrence and distribution of the species viz., herbarium records and published literature (World Conservation Monitoring Centre 1998; Nayar and Sastry 1987; Haridasan and Rao 1985), we presume that the landscapes in the Garo, Khasi, and Jaintia Hills have been accessible to the dispersal of the species. Therefore, model calibration was done in these areas.

We used a machine-learning algorithm, Maxent version 3.3.3e (Phillips et al. 2006), to model species potential habitats. Maxent computes the suitability of a pixel (corresponds to the grid of a given size in the real world) in a defined landscape by contrasting random background pixels against the ones with actual species presence (Merow et al. 2013). The landscape is characterized by a set of rasterized environmental variables such as temperature, precipitation, vegetation index, and the species real presence in the raster grids are indicated by geographic coordinates. Thus, it estimates a probability surface representing the distribution of pixels with a suitability range from 0 to 1 (Elith et al. 2011).

In the present study, model parameterization was done using 10,000 background points, 5000 iterations, and a convergence threshold of 0.00001 . Because of lower presence records, the hinge, linear and quadratic feature types were used to optimize complexity in model-fitting. Over-fitting was controlled using default regularization multiplier of 1 . Ten replicated model runs with bootstrap procedure was executed to derive an optimized model.

Model performance was assessed based on the traditional receiver operating characteristic (ROC) curve and area under curve (AUC) metric (Phillips et al. 2006). Here, an AUC value of $\leq 0.5$ indicates a performance that is no better than random expectations, whereas, a value of one indicates perfect discrimination (Thuiller et al. 2005). Model classification was done using the conservative guide suggested by Thuiller et al. (2005), i.e., random (AUC $<0.8)$, fair $(0.8<\mathrm{AUC}<0.9)$, good $(0.9<$ AUC $<0.95)$, and very good $(0.95<\mathrm{AUC}<1.0)$. To ensure consistency of model performance, we also employed the partial AUC metric (Lobo et al. 2008, Peterson et al. 2008). Partial AUC was estimated using the online tool http://shiny.conabio.gob.mx:3838/ 
nichetoolb2/. Here, the ratio between $\mathrm{AUC}_{\text {random }}$ (at 0.5 level) and the $\mathrm{AUC}_{\text {actual }}$ (with a defined level of omission, e.g., 0.05) was calculated using the occurrence data and the predicted distribution model, and gives a graphical output of the distribution of the estimated random and actual AUC values, along with $t$ tests for the difference between the distributions. For this study, we executed 500 bootstrap simulations with $5 \%$ omission to obtain the distribution of AUC ratios. Finally, hypothesis testing was done by comparing the means between $\mathrm{AUC}_{\text {random }}$ and $\mathrm{AUC}_{\text {partial }}$ to test whether the predictive model performed better than random expectations.

\section{Identification and characterization of potential habitats}

The potential habitat distribution map was generated using ArcMap by dividing the probability range into five classes, i.e., very high $(>0.8)$, high $(0.6-0.8)$, moderate $(0.4-0.6)$, low $(0.2-0.4)$, and very low $(<0.2)$. Subsequently, field surveys were undertaken from January 2016 to July 2017 for ground verification of the predicted potential habitats and searching new populations. Habitat characterization was done based on topographic features (viz., elevation, slope angle, slope orientation, and soil type), forest/vegetation type, and tree canopy cover. Slope orientation and elevation were determined using a GPS device (Garmin e-trex), and slope angle was measured using a clinometer. Vegetation type was determined following Champion and Seth (1968) classification, and the associated species were identified with the help of regional flora (Haridasan and Rao 1985-1987; Kanjilal et al. 1934-1940).

\section{Relationship between species abundance and habitat suitability}

The relationship between species abundance and habitat suitability was determined by running simple linear regression models. Here, species abundance, expressed in terms of density of trees, saplings, and seedlings, was
Table 1 Result of model evaluation tests done using full and partial ROC-AUC measures. The mean value for $A \cup C_{\text {partial }}$ at 0.5 is 0.5

\begin{tabular}{|c|c|c|c|c|}
\hline $\begin{array}{l}\mathrm{ROC} \\
\text { space }\end{array}$ & $\begin{array}{l}\text { Omission } \\
\text { proportion }\end{array}$ & $\begin{array}{l}\text { Mean } \\
\mathrm{AUC} C_{\text {model }}( \pm \mathrm{SD})\end{array}$ & $\begin{array}{l}\text { Mean } \\
\text { AUC ratio }( \pm S D)\end{array}$ & $\begin{array}{l}P \text { value for } \\
\text { difference in } \\
\text { expected and } \\
\text { random } \\
\text { AUC } C_{\text {mean }}\end{array}$ \\
\hline$\overline{R O C_{\text {full }}}$ & 0 & $0.99( \pm 0.002)$ & - & - \\
\hline $\mathrm{ROC}_{\text {partial }}$ & 0.05 & $0.98( \pm 0.004)$ & $1.97( \pm 0.009)$ & 0 \\
\hline
\end{tabular}

regressed with the modeled habitat suitability thresholds using SPSS software.

\section{Results}

\section{Evaluation of model performance}

Tests of model performance yielded optimal results for $\mathrm{ROC}_{\text {full }}$ (mean AUC 0.99) and $\mathrm{ROC}_{\text {partial }}$ (mean AUC 0.98) (Table 1). The distribution of AUC ratios, calculated from the bootstrap values as $\mathrm{AUC}_{\mathrm{partial}} / \mathrm{AUC}_{\text {random }}$, was significantly greater than random expectations showing very good model consistency (Fig. 3).

\section{Analysis of variable contributions}

Jackknifing of the regularized training gain and the analysis of variable contributions reveal a strong influence of vegetation phenology on the distribution of potential habitats of A. griffithii (Fig. 4). The EVI data for the period of June and July together contributed $\sim 80 \%$ to the modeled distribution of the species (Table 2).

\section{Potential habitat distribution and characterization}

Only $0.68 \%$ of the total area of Meghalaya is highly suitable (15,506 ha), and $3 \%$ of the total area is suitable for medium to low levels (70,650 ha) (Fig. 5). The rest of the areas are predicted to be suitable at very low level. The (potential) habitats were distributed mostly in the fragmented sub-tropical broadleaf type of forests at

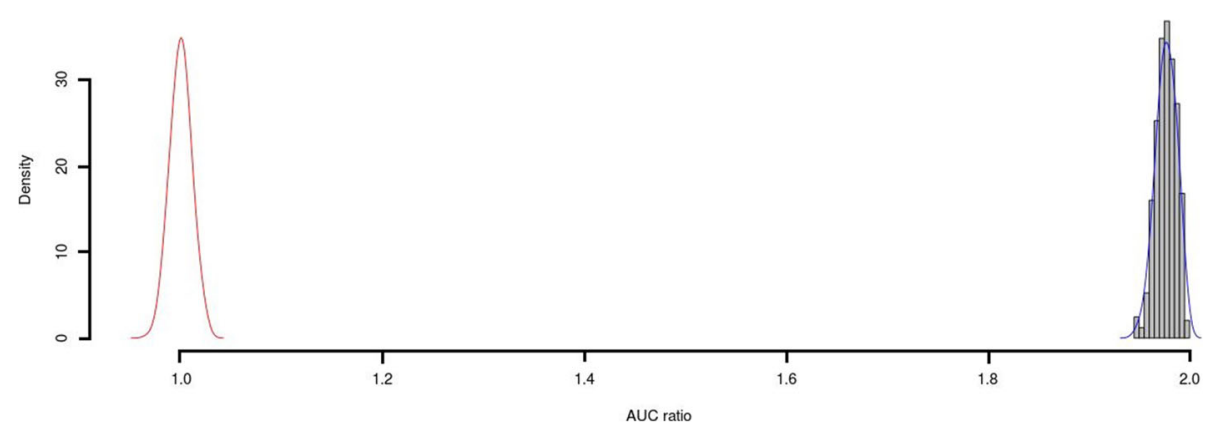

Fig. 3 Partial AUC distribution for A. griffithii generated after 500 iterations with 5\% omission in the ROC space. The curve along with the shaded bars shows the frequency distribution of the ratios between AUC from model prediction and $A U C_{\text {random. }}$ The curve on the left side represents the distribution of AUC ratios for random models. Here, the higher distributional range of AUC ratios indicates the better predictive ability of the Maxent model 


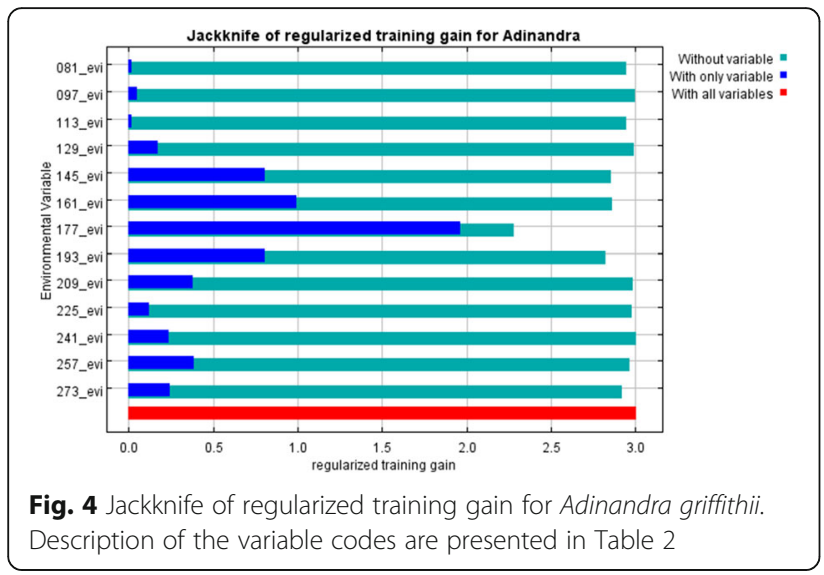

elevations ranging from $\sim 1200$ to $1600 \mathrm{~m}$ above mean sea level, of which sizable parts are in the Khasi hills (Fig. 2 and Table 3). In addition, field surveys revealed that degraded open forests, grasslands, small groves, cultivated areas, and homestead gardens may have suitable habitats, although at medium to low levels. Considerable areas of the highly suitable habitats were located on the hill slopes and had open, closed, and mixed canopy covers. The soil had sandy loam texture and was acidic in all the habitats.

\section{Population and regeneration status}

We inventoried 486 individuals comprising of 201 seedlings, 191 saplings, and 94 adults from the predicted area of occurrence. The largest number of adult trees were recorded from Lum Shynna in Cherrapunjee with 16 individuals followed by Law Adong Phlangmawsyrpat and Law Adong Kynshuilid with 10 individuals each (Table 3).

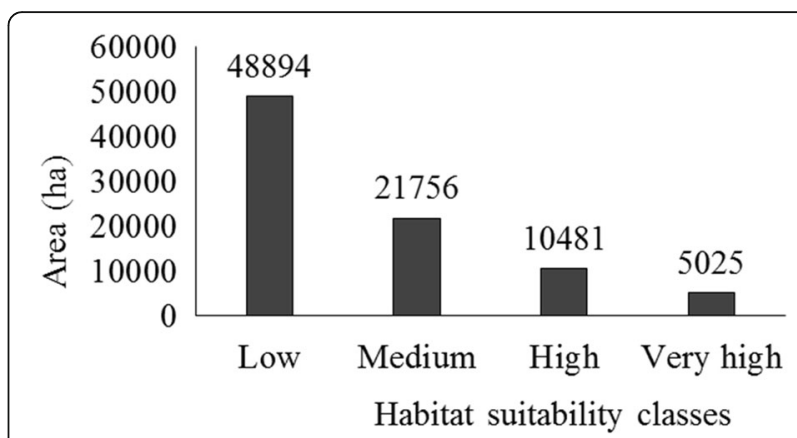

Fig. 5 Area under different habitat suitability classes. The figures on top of the bars represent the area in hectares

Relationship between abundance and habitat suitability Category wise, the high and very high suitability classes had greater abundance represented by 69 adults, 145 saplings, and 155 seedlings, compared to medium and low suitability classes comprising of 25 adults, 46 saplings, and 46 seedlings (Table 3 ). Linear regression shows a weak positive relation between abundance and the degree of habitat suitability for trees (slope $3.93 ; r$ 0.23; $p$ $0.36)$, though statistically not significant. However, sapling and seedling abundance had no particular relationship with habitat suitability.

\section{Discussion}

In the present study, remotely sensed vegetation phenology data (i.e., EVI) effectively discriminated the suitable and unsuitable habitats of $A$. griffithii. Nearly $80 \%$ contribution was made by the EVI layers pertaining to June and July, which is the flowering period of the species. Phenology can be a good predictor of species distribution as it is one of the important adaptive traits in the niche of perennial plants, plays a crucial role in their fitness, and is the trait

Table 2 Analysis of variable contributions

\begin{tabular}{|c|c|c|c|}
\hline Variable code & Month and date of EVI image & Percent contribution & Permutation importance \\
\hline 081 evi & March 22nd & 1.9 & 1.4 \\
\hline 097 evi & April 7th & 0.2 & 0.1 \\
\hline 113 evi & April 23rd & 2.0 & 0.6 \\
\hline 129 evi & May 9th & 0.5 & 0.2 \\
\hline 145 evi & May 25th & 8.7 & 1.6 \\
\hline 161 evi & June 10th & 7.5 & 5.4 \\
\hline 177 evi & June 26th & 58.6 & 85.3 \\
\hline 193 evi & July 12th & 13.6 & 1.3 \\
\hline 209 evi & July 28th & 1.0 & 0.2 \\
\hline 225 evi & August 13th & 1.2 & 0.3 \\
\hline $241 \mathrm{evi}$ & August 29th & 0.5 & 0.1 \\
\hline 257 evi & September 14th & 1.3 & 0.4 \\
\hline 273 evi & September 30th & 3.1 & 3.0 \\
\hline
\end{tabular}


Table 3 Species abundance, habitat attributes, and habitat suitability in the occurrence localities

\begin{tabular}{|c|c|c|c|c|c|c|c|c|c|c|c|}
\hline \multirow[t]{2}{*}{ Occurrence localities } & \multirow{2}{*}{$\begin{array}{l}\text { Predicted } \\
\text { suitability }\end{array}$} & \multirow{2}{*}{$\begin{array}{l}\text { Suitability } \\
\text { classes }\end{array}$} & \multicolumn{4}{|c|}{ Abundance (No. of individuals) } & \multicolumn{5}{|c|}{ Habitat attributes } \\
\hline & & & Adults & Sapling & Seedling & Total & $\begin{array}{l}\text { Elevation } \\
\text { (m) }\end{array}$ & Slope & Aspect & Forest type & $\begin{array}{l}\text { Canopy } \\
\text { cover }\end{array}$ \\
\hline Khlaw Jingkieng & 0.99 & Very high & 2 & 18 & 10 & 30 & 1420 & $\begin{array}{l}\text { Very } \\
\text { steep }\end{array}$ & $\mathrm{NE}$ & $\begin{array}{l}\text { Subtropical } \\
\text { Broadleaf }\end{array}$ & Open \\
\hline Lum Shynna & 0.98 & Very high & 16 & 22 & 26 & 64 & 1434 & $\begin{array}{l}\text { Very } \\
\text { steep }\end{array}$ & W & $\begin{array}{l}\text { Subtropical } \\
\text { Broadleaf }\end{array}$ & Closed \\
\hline $\begin{array}{l}\text { Law Adong } \\
\text { Kynshuilid }\end{array}$ & 0.87 & Very high & 10 & 2 & 0 & 12 & 1210 & Extreme & W & $\begin{array}{l}\text { Subtropical } \\
\text { Broadleaf }\end{array}$ & Open \\
\hline Law Adong Thmai & 0.85 & Very high & 2 & 2 & 0 & 4 & 1605 & $\begin{array}{l}\text { Very } \\
\text { steep }\end{array}$ & N & $\begin{array}{l}\text { Subtropical } \\
\text { Broadleaf }\end{array}$ & Mixed \\
\hline Tyllong Um-Kyrwiang & 0.79 & High & 5 & 11 & 18 & 34 & 1407 & Moderate & s & $\begin{array}{l}\text { Subtropical } \\
\text { Broadleaf }\end{array}$ & Closed \\
\hline $\begin{array}{l}\text { Law Arliang } \\
\text { Laitryngew }\end{array}$ & 0.77 & High & 1 & 5 & 12 & 18 & 1610 & Steep & N & $\begin{array}{l}\text { Subtropical } \\
\text { Broadleaf }\end{array}$ & Closed \\
\hline $\begin{array}{l}\text { Law Adong } \\
\text { Diengkynthong }\end{array}$ & 0.73 & High & 9 & 0 & 0 & 9 & 1610 & Steep & S & $\begin{array}{l}\text { Subtropical } \\
\text { Broadleaf }\end{array}$ & Open \\
\hline Law Khlieng & 0.72 & High & 8 & 22 & 21 & 51 & 1410 & $\begin{array}{l}\text { Very } \\
\text { steep }\end{array}$ & SE & $\begin{array}{l}\text { Subtropical } \\
\text { Broadleaf }\end{array}$ & Closed \\
\hline Law Pjah & 0.71 & High & 2 & 0 & 1 & 3 & 1605 & $\begin{array}{l}\text { Very } \\
\text { steep }\end{array}$ & S & $\begin{array}{l}\text { Subtropical } \\
\text { Broadleaf }\end{array}$ & Mixed \\
\hline $\begin{array}{l}\text { Balpakram National } \\
\text { Park }\end{array}$ & 0.68 & High & 5 & 15 & 23 & 43 & 586 & $\begin{array}{l}\text { Very } \\
\text { steep }\end{array}$ & S & $\begin{array}{l}\text { Tropical } \\
\text { Broadleaf }\end{array}$ & Closed \\
\hline Law Sunnia & 0.67 & High & 4 & 27 & 35 & 66 & 1210 & $\begin{array}{l}\text { Very } \\
\text { steep }\end{array}$ & E & $\begin{array}{l}\text { Subtropical } \\
\text { Broadleaf }\end{array}$ & Mixed \\
\hline $\begin{array}{l}\text { Mawsynram village } \\
\text { forest }\end{array}$ & 0.66 & High & 5 & 21 & 9 & 35 & 1430 & Extreme & NW & $\begin{array}{l}\text { Subtropical } \\
\text { Broadleaf }\end{array}$ & Closed \\
\hline $\begin{array}{l}\text { Law Lyngdoh } \\
\text { Lynshing }\end{array}$ & 0.58 & Medium & 4 & 11 & 18 & 33 & 1230 & $\begin{array}{l}\text { Very } \\
\text { steep }\end{array}$ & E & $\begin{array}{l}\text { Subtropical } \\
\text { Broadleaf }\end{array}$ & Mixed \\
\hline $\begin{array}{l}\text { Law Adong } \\
\text { Phlangmawsyrpat }\end{array}$ & 0.55 & Medium & 10 & 11 & 9 & 30 & 1240 & Extreme & NE & $\begin{array}{l}\text { Subtropical } \\
\text { Broadleaf }\end{array}$ & Closed \\
\hline Twah Sangparat & 0.33 & Low & 2 & 2 & 0 & 4 & 1425 & Steep & S & $\begin{array}{l}\text { Subtropical } \\
\text { Broadleaf }\end{array}$ & Open \\
\hline $\begin{array}{l}\text { Law Adong } \\
\text { Phud Juad }\end{array}$ & 0.33 & Low & 2 & 4 & 6 & 12 & 1400 & Gentle & SE & $\begin{array}{l}\text { Subtropical } \\
\text { Broadleaf }\end{array}$ & Closed \\
\hline $\begin{array}{l}\text { Umlangmar Law } \\
\text { Shnong }\end{array}$ & 0.27 & Low & 7 & 18 & 13 & 38 & 1600 & Steep & SW & $\begin{array}{l}\text { Subtropical } \\
\text { Broadleaf }\end{array}$ & Open \\
\hline Total & & & 94 & 191 & 201 & 486 & & & & & \\
\hline
\end{tabular}

Slope $\left({ }^{\circ}\right)$ : Level $(0)$, nearly level (0.3-1.1), very gentle (1.1-3), gentle (3-5), moderate (5-8.5), strong (8.5-16.5), very strong (16.5-24), extreme (24-35), steep (35-45), very steep ( $>45)$. The 'predicted suitability' values for the occurrence localities have been extracted from the logistic output of Maxent. The occurrence localities have been grouped under various suitability classes based on the range of predicted suitability values as very high (0.8-1.0), high (0.6-0.8), medium (0.4-0.6), low $(0.2-0.4)$, and very low $(<0.2)$

most affected by the change in climate (see Chuine 2010). Nonetheless, it is well-known that the position of a species niche is correlated with the flowering time, and members of a species growing in a given climatic zone synchronize their phenologies (Thuiller et al. 2005). Earlier, EVI was effectively used to predict the potential habitats for Ilex khasiana, an endangered endemic tree in the same region (Adhikari et al. 2012). Thus, EVI-based habitat suitability assessment is promising for population survey and species conservation.

Our study revealed a positive-though weak-correlation between species abundance and habitat suitability in an ecological space. This is in conformity with the abundance-center hypothesis which posits theoretical maxima of species abundance in the central part of a given landscape, which decline towards the edges (Sagarin et al. 2006). This theoretical maxima result from the presence of optimal environmental conditions in the central part of the distributional range of the species compared to its edges. Nevertheless, the geographical representation of the same revealed that the suitable habitats and individuals of the species, and therefore the abundance peaks, are distributed across the Garo, Khasi, and Jaintia hills. This phenomenon is a geographical 
manifestation of Hutchinsons' duality concept, which elucidates the connection between a species' ecological niche and its corresponding biotope, as well as the reciprocity in projections between them (Colwell and Rangel 2009). Nonetheless, the role of anthropogenic factors such as habitat/forest fragmentation in creating environmental/spatial heterogeneity cannot be ignored, as their effects are often not noticeable in the ecological space. This is because of occurrence of similar environmental conditions in more than one geographical location. Forest fragmentation and habitat degradation often lead to discontinuity in the distribution of species as well as the suitable habitats and leading to the local extinction of the species (Lindenmayer and Fischer 2013; Krauss et al. 2010). This weakens the linearity and strength of the relationship between environmental suitability and species abundance, as evident from the present study.

The narrow distribution of A. griffithii, low population coupled with habitat fragmentation, and human disturbances is posing a serious threat to the species, and may lead to its global extinction. Low seedling recruitment and sapling establishment on the forest floor is a major constraint faced by the species. The seeds $(\sim 1 \mathrm{~mm}$ size $)$ mature in October-November and take nearly 45 days to germinate (Upadhaya et al. 2017). Field observations revealed that the newly germinated seedlings are exposed to moisture stress and low temperatures that extend from December to February (winter season), leading to seedling mortality. The highly suitable habitats of the species, distributed in patches at various pockets of the study area, is already under threat due to anthropogenic activities such as road construction, shifting cultivation, mining, and grazing. It is important to mention that the forest cover in these areas experienced a tremendous change in the last few decades (Sarma 2005; Sarma et al. 2016). Nevertheless, colonization and dispersal may play an important role in population dynamics in such a patchy landscape (Freckleton et al. 2006).

\section{Conclusions}

Based on the above, we conclude that relationship between species abundance and habitat suitability deteriorates in fragmented forest landscapes having anthropogenic influences. We recommend reinforcement of the depleted populations, as well as reintroductions in suitable areas using artificially raised seedlings for its conservation (Adhikari et al. 2012; Deka et al. 2017). Moreover, the suitable habitat patches may be connected through habitat corridors facilitating species migrations, enabling their long-term conservation.

\section{Abbreviations}

AS: Abundance Suitability; AUC: Area under curve; ENM: Ecological niche modeling; EVI: Enhanced Vegetation Index; GIS: Geographical Information
System; GPS: Global Positioning System; MODIS: Moderate resolution imaging spectroradiometer; NDVI: Normalized Difference Vegetation Index; ROC: Receiver operating characteristic

\section{Acknowledgements}

We are thankful to Botanical Survey of India, Eastern Regional Circle for allowing us to consult the herbarium. The help and cooperation received from the local people is also thankfully acknowledged.

\section{Funding}

The research was partially funded by the Ministry of Environment, Forest and Climate Change (MoEF and CC), Government of India in the form of a project (no. 14/25/2011-ERS/RE).

Availability of data and materials

Not applicable.

\section{Authors' contributions}

$\mathrm{DA}$ and $\mathrm{KU}$ conceived the idea and designed the experiment. AHM, VI, and DKR collected and compiled field data. Analysis and writing was done by DA, AHM, and VI. KU and DKR edited the manuscript. All the authors read and approved the manuscript.

Ethics approval and consent to participate

Not applicable

Consent for publication

Not applicable

Competing interests

The authors declare that they have no competing interests.

\section{Publisher's Note}

Springer Nature remains neutral with regard to jurisdictional claims in published maps and institutional affiliations.

\section{Author details}

${ }^{1}$ Department of Botany, North-Eastern Hill University, Shillong 793022, India. ${ }^{2}$ Department of Environmental Studies, North-Eastern Hill University, Shillong 793022, India. ${ }^{3}$ Department of Basic Sciences and Social Sciences, North-Eastern Hill University, Shillong 793022, India. ${ }^{4}$ Botanical Survey of India, Eastern Regional Centre, Shillong 793003, India.

Received: 13 October 2017 Accepted: 8 January 2018

Published online: 22 January 2018

\section{References}

Adhikari D, Barik SK, Upadhaya K (2012) Habitat distribution modelling for reintroduction of llex khasiana Purk., a critically endangered tree species of northeastern India. Ecol Eng 40:37-43

Balakrishnan NP (1981) Flora of Jowai, vol 1. Botanical Survey of India, Howrah, p 305

Barve N, Barve V, Jiménez-Valverde A, Lira-Noriega A, Maher SP, Peterson AT, Soberón J, Villalobos F (2011) The crucial role of the accessible area in ecological niche modeling and species distribution modeling. Ecol Model 222(11):1810-1819

Brown JH (1984) On the relationship between abundance and distribution of species. Am Nat 124(2):255-279

Brummitt NA, Bachman SP (2010) Plants under pressure-a global assessment: the first report of the IUCN sampled red list index for plants. Royal Botanic Gardens, Kew

Champion SH, Seth SK (1968) A revised survey of the forest types of India. Government of India Press, New Delhi

Chuine I (2010) Why does phenology drive species distribution? Philos Trans R Soc Lond Ser B Biol Sci 365(1555):3149-3160

Colwell RK, Rangel TF (2009) Hutchinson's duality: the once and future niche. Proc Natl Acad Sci 106:19651-19658

Deka K, Baruah PS, Sarma B, Borthakur SK, Tanti B (2017) Preventing extinction and improving conservation status of Vanilla borneensis Rolfe-a rare, endemic and threatened orchid of Assam, India. J Nat Conserv 37:39-46 
Elith J, Phillips SJ, Hastie T, Dudík M, Chee YE, Yates CJ (2011) A statistical explanation of MaxEnt for ecologists. Divers Distrib 17(1):43-57

Fischer J, Lindenmayer DB (2007) Landscape modification and habitat fragmentation: a synthesis. Glob Ecol Biogeogr 16(3):265-280

Freckleton RP, Watkinson AR, Green RE, Sutherland WJ (2006) Census error and the detection of density dependence. J Anim Ecol 75:837-851

Giovanelli JG, de Siqueira MF, Haddad CF, Alexandrino J (2010) Modeling a spatially restricted distribution in the Neotropics: how the size of calibration area affects the performance of five presence-only methods. Ecol Model 221(2):215-224

Hansen MC, Potapov PV, Moore R, Hancher M, Turubanova SA, Tyukavina A, Thau D, Stehman SV, Goetz SJ, Loveland TR, Kommareddy A, Egorov A, Chini L, Justice CO, Townshend JRG (2013) High-resolution global maps of 21stcentury forest cover change. Science 342:850-853

Haridasan K, Rao RR (1985-1987) Forest Flora of Meghalaya, vol 2. Bishen Singh Mahendrapal Singh, Dehradun, p 937

Hengeveld R, Haeck J (1982) The distribution of abundance. I. Measurements. J Biogeogr 9:303-316

Kanjilal VN, Kanjilal PC, Das A, De RN, Bor NL (1934-1940) Flora of Assam, vol 5. Government Press, Shillong

Krauss J, Bommarco R, Guardiola M, Heikkinen RK, Helm A, Kuussaari M, Lindborg R, Öckinger E, Pärtel M, Pino J, Pöyry J, Raatikainen KM, Sang A, Stefanescu C, Teder T, Zobel M, Steffan-Dewenter I (2010) Habitat fragmentation causes immediate and time-delayed biodiversity loss at different trophic levels. Ecol Lett 13(5): 597-605

Lindenmayer DB, Fischer J (2013) Habitat fragmentation and landscape change: an ecological and conservation synthesis. Island Press, Washington DC.

Lira-Noriega A, Manthey JD (2014) Relationship of genetic diversity and niche centrality: a survey and analysis. Evolution 68(4):1082-1093

Lobo JM, Jiménez-Valverde A, Real R (2008) AUC: a misleading measure of the performance of predictive distribution models. Glob Ecol Biogeogr 17(2):145-151

Matsushita B, Yang W, Chen J, Onda Y, Qiu G (2007) Sensitivity of the enhanced vegetation index (EVI) and normalized difference vegetation index (NDVI) to topographic effects: a case study in high-density cypress forest. Sensors 7(11):2636-2651

Merow C, Smith MJ, Silander JA (2013) A practical guide to MaxEnt for modeling species' distributions: what it does, and why inputs and settings matter. Ecography 36(10):1058-1069

Nayar PH, Sastry ARK (1987) Red data sheet. Red data book of Indian plants, vol 1, p 356

Peterson AT (2001) Predicting SPECIES' geographic distributions based on ecological niche modeling. Condor 103(3):599-605

Peterson (2011) is to be corrected as Peterson et al. 2011. The reference is as follows: Peterson AT, Soberón J, Pearson RG, Anderson RP, Martínez- Meyer E, Nakamura M, Araújo MB (2011) Ecological niches and geographic distributions, Monographs in Population Biology; no. 49. Princeton University Press, New Jersey

Peterson AT, Papeş M, Soberón J (2008) Rethinking receiver operating characteristic analysis applications in ecological niche modeling. Ecol Model 213(1):63-72

Phillips SJ, Anderson RP, Schapire RE (2006) Maximum entropy modeling of species geographic distributions. Ecol Model 190(3):231-259

Phillips SJ, Dudík M, Elith J, Graham CH, Lehmann A, Leathwick J, Ferrier S (2009) Sample selection bias and presence-only distribution models: implications for background and pseudo-absence data. Ecol Appl 19:181-197

Roy PS, Tomar S (2001) Landscape cover dynamics pattern in Meghalaya. Int J Remote Sens 22(18):3813-3825

Sagarin RD, Gaines SD (2002) The 'abundant centre' distribution: to what extent is it a biogeographical rule? Ecol Lett 5(1):137-147

Sagarin RD, Gaines SD, Gaylord B (2006) Moving beyond assumptions to understand abundance distributions across the ranges of species. Trends Ecol Evol 21(9):524-530

Sarma K (2005) Impact of coal mining on vegetation: a case study in Jaintia Hills district of Meghalaya, India. M.Sc thesis

Sarma PK, Sarma K, Sarma K, Nath KK, Talukdar BK, Huda MEA, Baruah B (2016) Analysis of land use/land cover changes and its future implications in Garo Hill region of Meghalaya: a geo-spatial approach. IJIREM 3(1):2350-0557

Setiawan Y, Yoshino K, Prasetyo LB (2014) Characterizing the dynamics change of vegetation cover on tropical forestlands using 250m multi-temporal MODIS EVI. Int J Appl Earth Obs Geoinf 26:132-144
Thuiller W, Lavorel S, Araújo MB, Sykes MT, Prentice IC (2005) Climate change threats to plant diversity in Europe. Proc Natl Acad Sci USA 102(23):8245-8250

Upadhaya K, Mir AH, Iralu V (2017) Reproductive phenology and germination behavior of some important tree species of Northeast India. Proc Nat Acad Sci India Section B: Biol Sci. https://doi.org/10.1007/s40011-017-0841-4

Upadhaya K, Thapa N, Lakadong NJ, Barik SK, Sarma K (2013) Priority areas for conservation in northeast India: a case study in Meghalaya based on plant species diversity and endemism. Int J Ecol Environ Sci 39(2):125-136

Waring RH, Coops NC, Fan W, Nightingale JM (2006) MODIS enhanced vegetation index predicts tree species richness across forested ecoregions in the contiguous USA. Remote Sens Environ 103(2):218-226

Warren DL, Glor RE, Turelli M (2010) ENMTools: a toolbox for comparative studies of environmental niche models. Ecography 33:607-611

Weber MM, Stevens RD, Diniz-Filho JAF, Grelle CEV (2016) Is there a correlation between abundance and environmental suitability derived from ecological niche modelling? A meta-analysis. Ecography 39:001-012

Whittaker RH (1975) Communities and ecosystems, 2nd edn. MacMillan Publishing Co, New York

World Conservation Monitoring Centre (1998) Adinandra griffithii. The IUCN Red List of Threatened Species1998:e.T32924A9742171. https://doi.org/10.2305/ IUCN.UK. 1998.RLTS.T32924A9742171.en

Wulff EV (1950) An introduction to historical plant geography. Chronica Botanica Company, Waltham

\section{Submit your manuscript to a SpringerOpen ${ }^{\circ}$ journal and benefit from:}

- Convenient online submission

- Rigorous peer review

- Open access: articles freely available online

- High visibility within the field

- Retaining the copyright to your article

Submit your next manuscript at $>$ springeropen.com 